Revista Destaques Acadêmicos, Lajeado, v. 11, n. 1, 2019. ISSN 2176-3070

DOI: http://dx.doi.org/10.22410/issn.2176-3070.v11i1a2019.2115

http://www.univates.br/revistas

\title{
ANÁLISE DA ENVIRONMENTAL DISCLOSURE DE CORPORAÇÕES COM SELO ISE DA BM\&FBOVESPA
}

\author{
Andréia Alberton ${ }^{1}$, Alexandre André Feil ${ }^{2}$
}

Resumo: As corporações, em nível mundial, estão sendo pressionadas por diversos stakeholders para evidenciarem informações ambientais positivas e negativas nos relatórios contábeis / sociais. Neste contexto, este estudo objetiva analisar a environmental disclosure nas corporações com selo Índice de Sustentabilidade Empresarial (ISE) da BM\&FBovespa. A metodologia empregada é a quantitativa, descritiva-exploratória e tem como procedimento técnico a documental, sendo a coleta de dados efetuada mediante checklist. Os principais resultados revelam que as evidenciações das informações ambientais ocorrem, em maior quantidade, no relatório de sustentabilidade, por outro lado, estas informações são escassamente evidenciadas no balanço patrimonial e na demonstração do resultado do exercício. As informações ambientais positivas são evidenciadas em sua maioria e poucas evidenciaram informações ambientais negativas. A evidenciação das informações ambientais diverge entre as corporações analisadas, não detectando padrões de informações divulgadas. As corporações com selo ISE com prejuízo contábil tiveram maior divulgação de informações ambientais quanto à quantidade de relatórios, o que se constatou através de uma correlação significativa. Conclui-se que as corporações com selo ISE possuem uma escassa environmental disclosure das informações ambientais, em especial, nos relatórios contábeis.

Palavras-chave: Contabilidade Ambiental. Environmental Disclosure. Correlação de Spearman.

\section{Introdução}

A importância atribuída ao meio ambiente, em nível global, intensificouse em função de problemas alarmantes, por exemplo, o esgotamento dos recursos naturais (renováveis e não renováveis) e a poluição do ar, água e do solo, que

1 Universidade do Vale do Taquari - Univates. Graduada em Ciências contábeis pela Universidade Univates.

2 Universidade do Vale do Taquari - Univates. Doutor em Qualidade Ambiental pela Universidade Feevale. Universidade do Vale do Taquari - Univates. Docente permenente do Programa de Pós Graduação Stricto Sensu Mestrado em Sistemas Ambientais Sustentáveis. 
geram efeitos negativos estrondosos na temperatura e no clima do Planeta. Estes problemas ambientais crescem em magnitude e severidade (RIBEIRO; NASCIMENTO; VAN BELLEN, 2009). Além disso, as corporações são intensas consumidoras de recursos naturais e fontes poluidoras em potencial, portanto, são responsáveis pela maior parcela dos problemas ambientais do planeta (CARNEIRO; DE LUCA; OLIVEIRA, 2008).

A redução destes problemas ambientais exige que os gestores e diretores empresariais considerem a variável ambiental na tomada de decisões, e adotarem posturas operacionais e tecnológicas para contribuir na ampliação da capacidade de suporte do planeta (BARBIERE, 2007). Esta reflexão corrobora com Borges, Rosa e Ensslin (2010) quando afirmam que apenas a visão do lucro empresarial é insuficiente para atingir suas ideologias, sendo assim, na continuação das corporações no futuro, estas devem atender as necessidades dos stakeholders e em especial o meio ambiente.

A contabilidade ambiental apresenta-se como um elo de ligação, no processo das comunicações dos aspectos ambientais, entre as corporações e a sociedade (FERREIRA; SILVA, 2006; CARNEIRO; DE LUCA; OLIVEIRA, 2008). Contribuindo, assim, no controle dos impactos ambientais o que fortalece a imagem da empresa frente aos stakeholders endógenos e exógenos (RIBEIRO, 2006; FERREIRA; SIQUEIRA; GOMES, 2009; BORGES; ROSA; ENSSLIN, 2010).

A environmental disclosure compreende as divulgações das informações ambientais corporativas nos demonstrativos contábeis, ou seja, esta divulgação ambiental também é denominada de disclosure ambiental ou evidenciação ambiental (BRAGA; OLIVEIRA; SALOTTI, 2009). Gray e Bebbington (2001) destacam que as corporações evidenciam as informações ambientais para: a) legitimar suas atividades; b) distrair a atenção de outros setores; c) melhorar sua imagem e vantagens competitivas; e d) ter direito à informação. Já os motivos de não evidenciar relacionam-se (GRAY; BEBBINGTON, 2001): a) ao custo da coleta dos dados e divulgação; $b$ ) a falta de incentivos; $c$ ) a inexistência de dados; e d) a ausência de questões legais.

Neste contexto, este estudo objetiva analisar as environmental disclosure dos relatórios contábeis e administrativas (sociais) das 20 maiores corporações (em faturamento) com selo do Índice de Sustentabilidade Empresarial (ISE) da BM\&FBovespa do ano de 2013. A motivação, deste estudo, vinculase a importância que a evidenciação das informações ambientais possui frente à prestação de contas aos stakeholders. Além disso, Murcia et al. (2008) constataram, em análise à literatura internacional, sobre a evidenciação das informações ambientais de 1997 a 2007, que nenhum dos 145 autores estava vinculado a universidades Brasileiras. Desta forma, é necessária maior quantidade de discussões e acredita-se que esta análise contribua na formação do conhecimento sobre a environmental disclosure. 


\section{Referencial Teórico}

\subsection{Contabilidade Ambiental}

A elaboração e o fornecimento de informações aos usuários endógenos e exógenos fazem parte dos objetivos da contabilidade (SOUZA; RIBEIRO, 2004). A evidenciação de impactos e/ou soluções ambientais das corporações pode fornecer informações úteis aos stakeholders e causar modificações (ganhos ou perdas) na situação patrimonial (FERREIRA; SILVA, 2006). As corporações que valorizam as relações com o meio ambiente e a mitigação dos impactos ambientais possuem a tendência de melhorar sua imagem junto aos stakeholders (PAIVA, 2009).

As informações contábeis fornecidas pelas corporações até o século XIX compreendiam basicamente as financeiras (TINOCO; KRAEMER, 2011). Porém, com o advento das informações de caráter social, na ciência contábil, ocorreu um prelúdio da contabilidade ambiental para reportar suas informações aos diversos stakeholders (TINOCO; KRAEMER, 2011).

A contabilidade ambiental surgiu com a necessidade de avaliar e mensurar os efeitos da atividade empresarial no meio ambiente (FERREIRA, 2003; ROVER; BORBA; MURCIA, 2009), e também como uma ferramenta estratégica para estabelecer um canal de comunicação entre empresa e sociedade (CARNEIRO; DE LUCA; OLIVEIRA, 2008). Portanto, a contabilidade ambiental compreende a identificação, mensuração e esclarecimento dos fatos econômico-financeiros que estejam vinculados com a proteção, recuperação e a preservação ambiental para evidenciar a situação patrimonial corporativa (BERGAMINI JUNIOR, 1999; LIMA et al., 2012).

A contabilidade ambiental, na mensuração dos impactos ambientais, possui um grau de complexidade, considerada uma das tarefas mais críticas no processo de contabilização, maior que da contabilidade societária, pois hodiernamente inexistem instrumentos adequados na sua mensuração (FERREIRA, 2003; RIBEIRO, 2006). Essa mensuração dos eventos ambientais deve observar que (FERREIRA, 2003): a) a unidade deve ser monetária; b) a avaliação dos componentes do ativo deve ser realizada pelos benefícios futuros; c) os passivos serem avaliados pelo valor presente da dívida; d) os passivos contingentes devem ser valorados pelo valor presente das situações adversas futuras; e) a representação de capitais equivalentes para a comparabilidade; f) a moeda dever ser isenta de variações do poder aquisitivo; e g) respeitar os efeitos do tempo nos capitais.

A contabilidade societária não foca as questões ambientais, pois (LEONARDO, 2001): a) os gestores são resistentes em divulgar seus passivos

ambientais; b) pela baixa consistência informacional; c) dificuldades na mensuração de passivos ambientais; e d) a preocupação em tornar público notícias negativas sobre as atividades corporativas. 
A discussão do tema ambiental em relatórios contábeis não é recente (RIBEIRO; NASCIMENTO; VAN BELLEN, 2009). O estudo pioneiro nesta área atribui-se a Belkaoui (1976), o qual realizou uma pesquisa nos relatórios de 50 corporações sobre o impacto da poluição em relação ao preço das ações, mas apenas nos anos 1990 foram direcionados esforços às pesquisas sobre a evidenciação das questões ambientais. No Brasil, o foco destas pesquisas centra-se na informação endógena e ao passivo ambiental (ROVER; ALVES; BORBA, 2006).

A ascensão da preocupação com a degradação ambiental é refletida nas informações divulgadas, visto que as corporações devem informar aos usuários seu comportamento em relação ao meio ambiente (ROVER; BORBA, 2006). Assim, a contabilidade colabora frente a environmental disclosure das informações ambientais ao identificar, mensurar, registrar e interpretar os fatos endógenos e exógenos das corporações (ROVER; BORBA, 2006).

\subsection{Environmental Disclosure}

A environmental disclosure é denominada como evidenciação ambiental ou disclosure ambiental (ROSA et al., 2011). A environmental disclosure se conceitua como a prestação de informações aos stakeholders públicos e privados, contendo informações financeiras e não financeiras, assim como qualitativas e quantitativas referentes aos aspectos e impactos ambientais corporativos (BURGWAL; DION; VIEIRA, 2014). A environmental disclosure também é definida como o instrumento pelo qual se torna possível realizar análises quanto aos resultados obtidos pela entidade (BRAGA, 2007). Portanto, corresponde à divulgação das informações sobre o desempenho das entidades nas questões ambientais, além da informação vinculada ao meio ambiental e ao patrimônio das corporações (FERREIRA; SIQUEIRA; GOMES, 2009). Objetivando, essencialmente, na redução da assimetria e aumento da comunicação das informações entre os gestores corporativos e os investidores (ROSA et al., 2011).

A identificação das informações pelos gestores, que devem ser evidenciadas, é realizada de acordo com a demanda e o entendimento do esgotamento do meio ambiente, a responsabilidade profissional e a complexidade do sistema (ambiental/humano) (ROSA et al., 2011). Portanto, os eventos e impactos compreendem a (TINOCO; KRAEMER, 2011): riscos, políticas, estratégias, alvos, custos, despesas, receitas, passivos ou qualquer outra informação relevante.

Quanto ao objeto da evidenciação contábil de natureza ambiental, Ribeiro (2006), recomenda que sejam evidenciados os seguintes aspectos: a) a natureza dos gastos e passivos ambientais nas demonstrações contábeis; b) medidas de proteção ambiental implementadas devido à legislação e seus resultados, por exemplo, volume de redução de emissões; c) quaisquer incentivos, por exemplo, concessões e incentivos fiscais do governo, em compensação às 
medidas de proteção ambiental; e d) quaisquer procedimentos materiais sobre as leis ambientais.

Estas informações, segundo Costa (2012), podem ser incluídas através de contas ambientais nas demonstrações contábeis já existentes ou escrituradas em um grupo segregado de contas, considerando o custo da elaboração e divulgação. Carvalho (2007) salienta que as contas societárias e as contas ambientais devem ser demonstradas em conjunto para representar a posição patrimonial global da empresa e não fragmentada.

As environmentals disclosures podem ser realizadas de forma compulsória, através de leis e regulamentos, e de forma voluntária, estas últimas com base em recomendações e diretrizes (ROVER; BORBA; MURCIA, 2009). A evidenciação compulsória relaciona-se àquela exigida por normas específicas, enquanto que a voluntária depende das decisões da administração corporativa o que, contudo, não a torna menos necessária ou relevante que a environmental disclosure compulsório (MIRANDA; MALAQUIAS, 2013). Portanto, independentemente de serem voluntárias ou compulsórias, as informações devem ser as mesmas para os diferentes grupos de usuários, com o objetivo de evitar a existência de grupos com informações privilegiadas (MIRANDA; MALAQUIAS, 2013).

A evidenciação ambiental, no Brasil, não é compulsória, sendo assim, considera-se voluntária (ROVER; BORBA; MURCIA, 2009). Portanto, existem recomendações e diretrizes contábeis como o Parecer de Orientação número 15/873 da Comissão de Valores Mobiliários (CVM), a resolução do Conselho Federal de Contabilidade NBC T $15^{4}$, ITG $13(\mathrm{R} 2)^{5}$ e a Norma e Procedimento de Auditoria (NPA) $11^{6}$. A environmental disclosure, no Brasil, é realizada através de diferentes formas, sem uniformidade e padronização, pois não possuem uma regulamentação obrigatória (SANTOS et al., 2001; TINOCO; KRAEMER, 2011). Neste sentido, estas corporações têm encontrado dificuldades que são impostas pelas normas contábeis na divulgação das informações junto às demonstrações contábeis societárias, ou seja, essas dificuldades não liberam a contabilidade da responsabilidade de informar aos usuários sobre os fatos relacionados com as questões ambientais (COSTA; MARION, 2007).

Os stakeholders consideram as informações e a evidenciação voluntária das informações ambientais divulgadas relevantes à tomada de decisão,

3 Procedimentos a serem observados pelas companhias abertas e auditores independentes na elaboração e publicação das demonstrações financeiras, do relatório da administração e do parecer de auditoria relativos aos exercícios sociais encerrados a partir de dezembro de 1987.

4 Informações de Natureza Social e Ambiental.

5 Altera a ITG 13 (R1) que dispõe sobre direitos a participações decorrentes de fundos de desativação, restauração e reabilitação ambiental.

6 Balanço e Ecologia. 
ou seja, não consideram apenas as demonstrações financeiras prioritárias (BERTHELOT; CORMIER; MAGNAN, 2003). As informações ambientais evidenciadas nos relatórios contábeis possuem diversas críticas (RIBEIRO; NASCIMENTO; VAN BELLEN, 2009), que se relacionam com a omissão de informações ambientais que poderiam prejudicar a corporação (DEEGAN; RANKIN, 1996).

A environmental disclosure possui potencialidades e oportunidades, onde as potencialidade referem-se à padronização da informação ambiental, gestão pelas sociedades (leis e normas) e pela corporação (consequências nos objetivos estratégicos) (ROSA et al., 2011). Já as oportunidades vinculam-se ao processo estruturado necessário para identificar, mensurar, apresentar, diagnosticar e aperfeiçoar (ROSA et al., 2011).

\subsection{Resultados de estudos precedentes sobre environmental disclosure}

O número de pesquisas com a temática das questões ambientais nas corporações e sua divulgação é crescente (CALIXTO, 2009). Santos et al. (2001) salientam que as corporações brasileiras com maior desempenho ambiental são aquelas que possuem maior inserção no mercado externo.

A análise de revisão bibliográfica, em nível nacional, realizada por Gallon et al. (2008), sobre a temática ambiental de 2000 a 2006, revela que a representação sobre o assunto contabilidade e evidenciação contábil foi de apenas 10\% do total das publicações. Já Epstein (2003) em pesquisa realizada, em 40 anos, revela que embora tenham aumentado o número de empresas que elaboram os relatórios ambientais, não houve uma melhoria na qualidade das informações divulgadas. Portanto, na sequencia apresenta-se o Quadro 1 e 2 contendo os estudos anteriores sobre a temática environmental disclosure de corporações nacionais e internacionais.

Quadro 1 - Estudos internacionais sobre environmental disclosure.

\begin{tabular}{|l|l|}
\hline Autor e Ano & \multicolumn{1}{c|}{ Principais resultados do estudo } \\
\hline $\begin{array}{l}\text { Belkaoui } \\
(1976)\end{array}$ & $\begin{array}{l}\text { Analisa os relatórios sobre o impacto da evidenciação ambiental nos } \\
\text { preços das ações (Bolsa de Valores), realizado em 50 corporações nos } \\
\text { EUA, em 1976. Os resultados apontam que existe uma correlação } \\
\text { entre o preço da ação e a divulgação das informações ambientais. }\end{array}$ \\
\hline $\begin{array}{l}\text { Wiseman } \\
(1982)\end{array}$ & $\begin{array}{l}\text { Avalia a qualidade e precisão das informações ambientais divulgadas } \\
\text { por 26 corporações industriais, ambientalmente sensíveis. Os } \\
\text { resultados revelam que as informações ambientais divulgadas são } \\
\text { incompletas e que não refletem o real desempenho ambiental. }\end{array}$ \\
\hline $\begin{array}{l}\text { Gray, Kouhy } \\
\text { e Lavers } \\
(1995)\end{array}$ & $\begin{array}{l}\text { Examinam as práticas de evidenciação em relatórios ambientais em } \\
\text { corporações do Reino Unido, de 1979 a 1991. Os resultados apurados } \\
\text { retratam que o comportamento da divulgação social e ambiental teve } \\
\text { uma mudança drástica no período analisado. }\end{array}$ \\
\hline
\end{tabular}




\begin{tabular}{|c|c|}
\hline Autor e Ano & Principais resultados do estudo \\
\hline $\begin{array}{l}\text { Niskala e } \\
\text { Pretes (1995) }\end{array}$ & $\begin{array}{l}\text { Analisam as mudanças dos relatórios ambientais em } 75 \text { corporações } \\
\text { Finlandesas de } 1987 \text { a 1992, de setor com maior sensibilidade } \\
\text { ambiental. Os resultados apontam mudanças nas práticas de relatórios } \\
\text { ambientais, sendo que a maior parte das divulgações compreendiam } \\
\text { informações qualitativas. }\end{array}$ \\
\hline Imam (2000) & $\begin{array}{l}\text { Analisa as características da informação ambiental evidenciada em } \\
40 \text { corporações com ações na bolsa de valores de Bangladesh de } \\
\text { diferentes setores de atuação, com dados de 1995-1996. Os resultados } \\
\text { apontam que a divulgação de informações ambientais é crescente, } \\
\text { porém muitas não divulgam as informação, além disto, os dados } \\
\text { eram qualitativos e o nível de divulgação é escasso. }\end{array}$ \\
\hline $\begin{array}{l}\text { O’Donovan e } \\
\text { Gibson (2000) }\end{array}$ & $\begin{array}{l}\text { Analisam a divulgação das informações ambientais de } 41 \text { empresas } \\
\text { australianas do setor químico, papel e celulose, petróleo e gás natural, } \\
\text { entre outros, de } 1983 \text { a 1997. Os resultados revelam um aumento } \\
\text { significativo na divulgação, e as informações ambientais divulgadas } \\
\text { constituíam-se na natureza descritiva. }\end{array}$ \\
\hline $\begin{array}{l}\text { Hughes, } \\
\text { Anderson e } \\
\text { Golden (2001) }\end{array}$ & $\begin{array}{l}\text { Analisam as divulgações ambientais em } 51 \text { corporações industriais nos } \\
\text { EUA de } 1992 \text { a } 1993 \text {. Os resultados apontam que existem diferenças } \\
\text { no grau em que as corporações divulgam as informações ambientais; } \\
\text { e as divulgações ambientais apenas retratam o impacto negativo } \\
\text { ambiental, ou seja, as de maior nível de evidenciação ambiental nos } \\
\text { relatórios são as piores na performance ambiental. }\end{array}$ \\
\hline Patten (2002) & $\begin{array}{l}\text { Analisa a divulgação dos relatórios ambientais e o desempenho } \\
\text { ambiental de } 131 \text { corporações nos EUA, de 1988. Os resultados } \\
\text { evidenciam que existe uma relação significativa negativa entre o } \\
\text { desempenho e a divulgação ambiental. }\end{array}$ \\
\hline Nossa (2002) & $\begin{array}{l}\text { Analisa os relatórios ambientais de } 42 \text { corporações, do setor de papel } \\
\text { e celulose em nível internacional, em } 2002 \text {. Os resultados mostram } \\
\text { que o disclosure ambiental diverge entre as empresas em função do } \\
\text { tamanho, do país de localização e o tipo de relatório (financeiro ou } \\
\text { específico). }\end{array}$ \\
\hline $\begin{array}{l}\text { Campbell } \\
(2004)\end{array}$ & $\begin{array}{l}\text { Investigou as informações ambientais divulgadas em } 264 \text { corporações } \\
\text { Britânicas, dos setores: varejista, petroquímica, química, entre outros, } \\
\text { de } 1974 \text { a 2000. Os resultados indicam uma associação positiva entre } \\
\text { o environmental disclosure e a vulnerabilidade estrutural em relação } \\
\text { aos passivos ambientais; e que houve um aumento das informações } \\
\text { ambientais divulgadas, especialmente a partir da década de } 1980 \text {. }\end{array}$ \\
\hline $\begin{array}{l}\text { Kuasirikun e } \\
\text { Sherer (2004) }\end{array}$ & $\begin{array}{l}\text { Analisam as características das divulgações de informações ambientais } \\
\text { em } 54 \text { corporações, referente ao ano de } 1993 \text { e } 65 \text { corporações de } \\
\text { 1999, na Tailândia, de diversos setores. Os resultados revelam que a } \\
\text { descrição das informações ambientais está aquém da potencialidade } \\
\text { de transmitir a comunicação. }\end{array}$ \\
\hline
\end{tabular}




\begin{tabular}{|l|l|}
\hline Autor e Ano & \multicolumn{1}{c|}{ Principais resultados do estudo } \\
\hline $\begin{array}{l}\text { Cowan e } \\
\text { Gadenne } \\
(2005)\end{array}$ & $\begin{array}{l}\text { Examinam as práticas de divulgação de relatórios ambientais em } \\
25 \text { corporações australianas, de diferentes setores de atuação, de } \\
1998 \text { a 2000. Os resultados apontam as divulgações realizadas sob } \\
\text { requisitos legislados recebem uma abordagem diferente, e em menor } \\
\text { quantidade; e além disto, apresentam mais informações negativas do } \\
\text { que as divulgações voluntárias. }\end{array}$ \\
\hline $\begin{array}{l}\text { Murray et al. } \\
(2006)\end{array}$ & $\begin{array}{l}\text { Analisam a relação entre o comportamento das ações (preço) no } \\
\text { mercado acionário e as informações sociais e ambientais divulgadas } \\
\text { em 100 corporações Inglesas, compreendendo diferentes setores. Os } \\
\text { resultados não apontam nenhuma relação entre o comportamento do } \\
\text { preço das ações e as informações sociais e ambientais. }\end{array}$ \\
\hline $\begin{array}{l}\text { Chatterjee e } \\
\text { Mir (2008) }\end{array}$ & $\begin{array}{l}\text { Exploram os relatórios ambientais de 45 corporações indianas, de 2003 } \\
\text { a 2004, de diferentes setores de atuação. Os resultados revelam que as } \\
\text { corporaçes divulgam maior quantidade de informações ambientais } \\
\text { anuais. }\end{array}$ \\
\hline
\end{tabular}

Fonte: Elaborado pelos próprios autores.

Quadro 2 - Estudos nacionais sobre environmental disclosure.

\begin{tabular}{|c|c|}
\hline Autor e Ano & Principais resultados do estudo \\
\hline $\begin{array}{l}\text { Borba e } \\
\text { Nazário } \\
(2003)\end{array}$ & $\begin{array}{l}\text { Examinam os relatórios contábeis de } 37 \text { empresas Brasileiras de } 10 \\
\text { setores potencialmente poluidoras, do ano de 2002. Os resultados } \\
\text { revelam que as evidenciações ambientais ocorrem principalmente no } \\
\text { relatório da administração, e em menor escala nas notas explicativas; } \\
\text { e as provisões ambientais evidenciadas no balanço patrimonial foram } \\
\text { das empresas do setor siderúrgica e metalúrgica. }\end{array}$ \\
\hline Calixto (2004) & $\begin{array}{l}\text { Examinam as } 10 \text { maiores empresas do setor de mineração em nível } \\
\text { global. Os resultados indicam que a legislação e a cultura do país } \\
\text { de origem da corporação definem a quantidade e a quantidade } \\
\text { informacional divulgada nos relatórios. }\end{array}$ \\
\hline Ben (2005) & $\begin{array}{l}\text { Evidencia as divulgações de informações ambientais nas } \\
\text { demonstrações contábeis de 2004, no estado do Rio Grande do Sul, } \\
\text { em } 31 \text { corporações, de diversos setores. Os resultados apontam uma } \\
\text { ausência da divulgação de informações ambientais nos relatórios. }\end{array}$ \\
\hline
\end{tabular}




\begin{tabular}{|c|c|}
\hline Autor e Ano & Principais resultados do estudo \\
\hline $\begin{array}{l}\text { Ferreira e } \\
\text { Silva }(2006)\end{array}$ & $\begin{array}{l}\text { Identificam a divulgação de elementos ambientais mediante a } \\
\text { contabilidade de cinco corporações Brasileiras do setor de atuação } \\
\text { siderúrgico, a análise ocorreu nos relatórios contábeis de } 2001 \text { a } \\
\text { 2003. Os resultados apontam a existência de uma preocupação das } \\
\text { siderurgias com o meio ambiente por meio de ações, implementações } \\
\text { e evidenciações ambientais. A divulgação das informações ambientais } \\
\text { ocorre através do relatório da administração, sites institucionais } \\
\text { e relatórios ambientais específicos, com ênfase em informações } \\
\text { descritivas qualitativas. }\end{array}$ \\
\hline $\begin{array}{l}\text { Costa e } \\
\text { Marion } \\
(2007)\end{array}$ & $\begin{array}{l}\text { Examinam as informações ambientais disponíveis, quanto a } \\
\text { uniformidade, nos sites da BM\&FBovespa de oito corporações, } \\
\text { com dados de 2003-2004, compreendem o setor celulose e papel. O } \\
\text { resultado exprime uma dificuldade quanto à análise das informações } \\
\text { ambientais, em função da ausência de uniformidade das estruturas } \\
\text { destes relatórios. }\end{array}$ \\
\hline $\begin{array}{l}\text { Rover, Borba } \\
\text { e Murci } \\
(2009)\end{array}$ & $\begin{array}{l}\text { Identificam as características das informações ambientais divulgadas } \\
\text { em } 57 \text { corporações de capital aberto (BM\&FBovespa) tendo como base } \\
\text { o período temporal de } 2005 \text { a 2007, em diversos setores. Os resultados } \\
\text { apontam que a maior parte da evidenciação é declarativa, contendo } \\
\text { informações ambientais positivas; e houve escassa divulgação de } \\
\text { informações negativas relacionadas às questões ambientais. }\end{array}$ \\
\hline Calixto (2009) & $\begin{array}{l}\text { Examina as informações ambientais evidenciadas em } 80 \text { corporações } \\
\text { brasileiras de capital aberto, que atuam em } 17 \text { setores distintos, } \\
\text { este exame ocorreu com relatórios de } 1997 \text { a } 2005 \text {. Os resultados } \\
\text { apontam um aumento na quantidade de informações ambientais } \\
\text { divulgadas, em especial no relatório da administração. A divulgação } \\
\text { de informações ambientais vincula-se a cultura dos gestores. }\end{array}$ \\
\hline $\begin{array}{l}\text { Ribeiro, } \\
\text { Nascimento } \\
\text { e Van Bellen } \\
(2009)\end{array}$ & $\begin{array}{l}\text { Avaliam o nível de evidenciação ambiental em } 16 \text { corporações } \\
\text { brasileiras, } 20 \text { corporações britânicas e } 15 \text { corporações dos EUA, de } \\
\text { três setores de atuação: água e saneamento, petróleo e siderurgia, } \\
\text { e sua análise ocorreu de } 2006 \text { a } 2007 \text {. Os resultados revelam que o } \\
\text { maior índice de evidenciação ambiental atribui-se a Inglaterra, } \\
\text { na sequencia os EUA e o Brasil. O setor com maior evidenciação } \\
\text { ambiental compreende a água e saneamento. Entre as demonstrações } \\
\text { utilizadas para a evidenciação destacam-se as notas explicativas, e o } \\
\text { Brasil aparece em primeiro lugar, seguido pelos EUA. }\end{array}$ \\
\hline $\begin{array}{l}\text { Borges, Rosa } \\
\text { e Ensslin } \\
(2010)\end{array}$ & $\begin{array}{l}\text { Investigam a evidenciação ambiental voluntária das } 18 \text { maiores } \\
\text { corporações do setor de atuação do papel e celulose, de } 2007 \text {. Os } \\
\text { resultados apontam que a maioria das corporações apresentam } \\
\text { as políticas ambientais, porém nas divulgações de informações } \\
\text { apresentam apenas informações de caráter descritivo. }\end{array}$ \\
\hline
\end{tabular}




\begin{tabular}{|c|c|}
\hline Autor e Ano & Principais resultados do estudo \\
\hline $\begin{array}{l}\text { Sousa, Rásia } \\
\text { e Jacques } \\
(2010)\end{array}$ & $\begin{array}{l}\text { Analisam as informações ambientais evidenciadas nos relatórios } \\
\text { contábeis de } 2007 \text { e } 2008 \text { de } 13 \text { corporações Brasileiras com selo } \\
\text { ISE, do setor de atuação de energia elétrica, química e siderurgia e } \\
\text { metalúrgica. Os resultados apontam que a informação ambiental é } \\
\text { divulgada pelobalanço social, em seguida o relatório deadministração, } \\
\text { e uma terça parte utiliza as notas explicativas; e que há uma carência } \\
\text { na exploração dos indicadores ambientais. }\end{array}$ \\
\hline
\end{tabular}

Fonte: Elaborado pelos próprios autores.

Uma breve análise dos estudos descritos nos Quadros 1 e 2 demonstram que as evidenciações no decorrer do tempo tiveram um crescimento, mas principalmente de informações qualitativas e descritivas. Estas evidenciações ambientais, em sua maioria, foram informadas em relatórios não financeiros, o que não afeta as questões patrimoniais e econômicas nas corporações. Salientase, também, que as informações ambientais divulgadas diferem dependendo do porte, do país de localização e da cultura na qual os gestores e as corporações estão inseridos; e a grande parte das corporações analisadas nos estudos vincula-se a setores potencialmente poluidores do meio ambiental.

\section{Procedimentos metodológicos}

\subsection{Tipo de pesquisa e a Unidade de análise}

A pesquisa classifica-se quanto à abordagem como quantitativa, de caráter descritivo-exploratório. A carteira ISE de 2013 é composta por 37 corporações, que representam 16 setores e somam $\mathrm{R} \$ 1,07$ trilhões em valor de mercado (ISE, 2015). A carteira ISE da BM\&FBovespa apresenta as corporações, com capital aberto, com elevado nível de sustentabilidade (FEIL; NAIME, 2015). A escolha desta carteira de 2013 das corporações da ISE ocorreu, principalmente, em função da realização, deste estudo, ter ocorrido em agosto a dezembro de 2014, desta forma, a última disponibilidade dos relatórios contábeis/sociais destas corporações compreendia o ano base de 2013. A amostra selecionada, compreende apenas as 20 corporações (QUADRO 3) com o maior valor de receita operacional bruta, esta escolha se deve em função da disponibilidade temporal para a pesquisa, e o critério utilizado em função do maior esforço para geração de receita.

Quadro 3 - Corporações selecionadas da carteira ISE 2013.

\begin{tabular}{|l|c|}
\hline \multicolumn{2}{|c|}{ Amostra das corporações com selo ISE } \\
\hline Banco do Brasil S.A. & $\begin{array}{c}\text { Gerdau Met - Metalúrgica Gerdau } \\
\text { S.A }\end{array}$ \\
\hline Banco Bradesco S.A. & Itaú Unibanco Holding S.A. \\
\hline
\end{tabular}




\begin{tabular}{|c|c|}
\hline Braskem S.A. & $\begin{array}{c}\text { Sabesp - CIA de Saneamento Básico } \\
\text { do Estado de São Paulo }\end{array}$ \\
\hline BRF S.A. & Santander - Banco Santander Brasil S.A. \\
\hline Cemig - CIA Energética de Minas Gerais & Sul América S.A. \\
\hline Copel - CIA Paranaense de Energia & Telefônica Brasil S.A. \\
\hline CPFL Energia S.A. & Telemar Participações S.A. \\
\hline Eletrobrás - Centrais Elétricas Brasileiras S.A. & Tim Participações S.A. \\
\hline Eletropaulo Metrop. Elet. São Paulo S.A. & Ultrapar Participações S.A. \\
\hline Gerdau S.A. & Vale S.A. \\
\hline
\end{tabular}

Fonte: Elaborado pelos autores.

\subsection{Procedimentos na coleta, tratamento e análise dos dados.}

A coleta dos dados realizou-se por meio de fontes secundárias, compreendendo os: a) relatórios contábeis: Balanço Patrimonial (BP), Demonstração dos Resultados do Exercício (DRE), Notas Explicativas (NE); e b) relatórios sociais/administrativos: Relatório da Administração (RA), Relatório de Sustentabilidade (RS) e o Relatório Ambiental (RL), compreendendo o ano base 2013. A coleta ocorreu diretamente do site da BM\&FBovespa (http:/ / www. bmfbovespa.com.br/), acessando a aba Mercados/Ações/Empresas/Empresas Listadas. Neste link, foram identificadas as 20 corporações da amostra. Após a identificação das corporações, selecionou-se a aba Informações Relevantes para a coleta dos relatórios de sustentabilidade, e no link Relatórios Financeiros / Demonstrações Financeiras Padronizadas coletou-se os demais relatórios contábeis. O período desta coleta ocorreu em agosto de 2014.

Após coletar os relatórios contábeis / sociais, utilizou-se um checklist para tratamento dos dados mediante a técnica de análise de conteúdo (ver em Bardin, 2004), este procedimento ocorreu em setembro de 2014. Os dados coletados nos relatórios contábeis/sociais estão vinculados a: a) Informações de natureza ambiental (identificação em qual relatório foi evidenciada): Apresentação do Relatório Ambiental, Apresentação do Relatório de Sustentabilidade, Evidenciação dos custos ambientais anuais pelas corporações, Evidenciação de Despesas Ambientais, Evidenciação dos Ativos Ambientais, Evidenciação dos Passivos Ambientais, Investimentos e gastos com prevenção e/ou recuperação ambiental, Investimentos e gastos com projetos ambientais, Investimentos e gastos para melhoria do meio ambiente, existência de Projetos ambientais, Passivos e Contingências Ambientais, Existência de processos ambientais, administrativos e judiciais movidos contra a corporação, Existência de cobranças de multas e indenizações ambientais via administrativa ou judicial; e b) características da corporação: atividade, anos de mercado, região/sede e o resultado do exercício. A seleção destas informações coletadas ocorreu com base nos estudos de Ferreira e Silva (2006) e Souza, Rásia e Jacques (2010). 
Os dados coletados pelo checklist foram tabulados e organizados com o auxílio do software Microsoft Office Excel. A tabulação das informações coletadas foi codificada por meio da codificação numérica (TABELA 1), sendo assim, é possível sua utilização para a identificação de correlações com base no software IBM SPSS 21.

Tabela 1 - Tabulação das informações coletadas

\begin{tabular}{|c|c|c|c|c|c|c|c|}
\hline \multicolumn{2}{|c|}{$\begin{array}{c}\text { Região/ } \\
\text { sede }\end{array}$} & \multicolumn{2}{|c|}{ Relatório contábil } & \multicolumn{2}{|l|}{ Atividade } & \multicolumn{2}{|c|}{$\begin{array}{c}\text { Resultado do } \\
\text { exercício }\end{array}$} \\
\hline 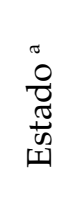 & 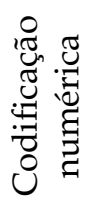 & 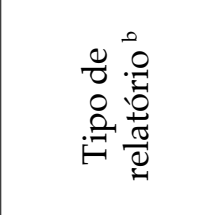 & 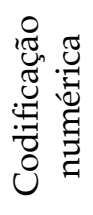 & 苋 & 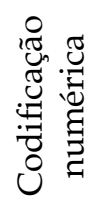 & 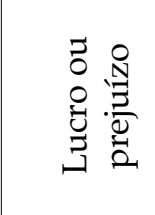 & 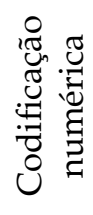 \\
\hline RS & 1 & BP & 1 & Mineração & 1 & Lucro & 1 \\
\hline PR & 2 & DRE & 2 & $\begin{array}{l}\text { Químico e } \\
\text { Petroquímico }\end{array}$ & 1 & Prejuízo & 2 \\
\hline SC & 3 & NE & 3 & $\begin{array}{l}\text { Siderurgia e } \\
\text { Metalurgia }\end{array}$ & 1 & & \\
\hline SP & 4 & RA & 4 & Alimentos & 1 & & \\
\hline RJ & 5 & RS & 5 & Telecomunicações & 2 & & \\
\hline $\mathrm{DF}$ & 6 & RL & 6 & Saneamento básico & 2 & & \\
\hline \multirow[t]{7}{*}{ MG } & 7 & $\mathrm{BP}, \mathrm{NE}$ & 7 & Energia Elétrica & 2 & & \\
\hline & & NE, RS & 8 & $\begin{array}{l}\text { Seguradora e } \\
\text { financeiro }\end{array}$ & 3 & & \\
\hline & & NE, RA & 9 & & & & \\
\hline & & RA, RS & 10 & & & & \\
\hline & & NE, RA, RL & 11 & & & & \\
\hline & & RA, RS, RL & 12 & & & & \\
\hline & & $\begin{array}{l}\text { BP, NE, RA, } \\
\text { RS }\end{array}$ & 13 & & & & \\
\hline
\end{tabular}

Fonte: Elaborado pelos autores. Legenda: ${ }^{\mathrm{O}} \mathrm{O}$ estado de cada corporação foi ordenado atribuindose as localidades do sul uma codificação numérica 1 e quanto mais localizadas ao norte maior foi a codificação atribuída. ${ }^{\mathrm{b}} \mathrm{O}$ relatório codificados como 1 compreende o mais compulsória quanto a confecção e divulgação, e quanto maior, até 6 , a codificação menor é sua obrigatoriedade. Já a codificação de 7 a 13 observa-se a quantidade de relatórios emitidos e a obrigatoriedade de publicação. ${ }^{c} \mathrm{O}$ setores das corporações foram codificados observando-se o grau de poluição, para as corporações com alto grau de poluição codificou-se 1 , as de médio 2 e as de pequeno potencial 3, de acordo com a Lei número 10.165 de 2000. 
Com base nestas tabulações foi possível realizar os testes estatísticos relacionados às correlações de Spearman, a fim de pesquisar o relacionamento linear entre as informações obtidas, determinando o grau de significância de tais correlações. O coeficiente de correlação de Spearman é uma estatística não paramétrica compreendendo medidas nominais e escalares (BISQUERRA; SARRIERA; MARTINEZ, 2004; FIELD, 2009). O coeficiente resultante da correlação de Spearman, segundo Mitra e Lankford (1999), avalia-se como: uma correlação baixa entre 0,20 a 0,39; moderada, entre 0,40 a 0,59; e forte, acima de 0,59. Bisquerra, Sarriera e Martinez (2004) e Field (2009) afirmam que quando o coeficiente compreende entre - 1 e 0 , esta análise da intensidade também é válida, mas compreende uma correlação negativa. Salienta-se que as correlações analisadas, neste estudo, compreendem apenas o nível de significância de 0,01, em função de seu grau de certeza apurada.

\subsection{Restrições e Limitações do Estudo}

Este estudo, apesar de estabelecer os critérios metodológicos, possui algumas limitações. As corporações selecionadas na amostra da pesquisa pertencem a um grupo específico, carteira da ISE da BM\&FBovespa, portanto não pode-se generalizar os resultados da pesquisa, bem como para as corporações não cadastradas na ISE.

Outra limitação ocorre com os relatórios contábeis/sociais utilizados na análise, pois todos foram extraídos do site da BM\&FBovespa, e não foram consultados sites das corporações selecionadas. Neste sentido, se outros estudos incluírem os relatórios, por exemplo, os disponibilizados nos sites das corporações, os resultados podem ser distintos daqueles apurados nesta pesquisa. Além disto, salienta-se que no Brasil não existe uma padronização frente a evidenciação das informações ambientais o que dificulta a comparabilidade dos dados entre corporações.

\section{Descrições e análises dos resultados}

\subsection{Análise da divulgação de informações ambientais}

A análise da coleta dos dados, sobre a divulgação de informações ambientais, demonstra que o relatório ambiental foi elaborado por $25 \%$ das corporações (TABELA 2), já o relatório de sustentabilidade por $85 \%$. Os custos e as despesas ambientais foram evidenciadas em apenas $5 \%$ das corporações e divulgadas no RS. Os ativos ambientais foram evidenciados por $10 \%$ das corporações, por meio do $\mathrm{BP}$ e das NE, enquanto que os passivos ambientais foram evidenciados por $15 \%$ das corporações, pelos mesmos relatórios, com predomínio do balanço patrimonial. Os investimentos e gastos com prevenção e/ou recuperação ambiental encontram-se presentes em $60 \%$ das corporações, 
desse percentual, $55 \%$ das informações foram apresentadas, principalmente, através do RS, RL e das NE, respectivamente.

Os investimentos e gastos com projetos ambientais foram evidenciados em $60 \%$ das corporações, com predomínio do RL e do RS. Os investimentos e gastos para melhorias do meio ambiente, representando 35\%, evidenciaram em seus RL e no RS. As informações descritas sobre os projetos ambientais foram evidenciadas por $70 \%$ das corporações, destes, $45 \%$ das evidenciações foram realizadas através dos RS, $20 \%$ nos RL e $5 \%$ nas NE. A evidenciação de passivos e contingências ambientais ocorreu em apenas $10 \%$ das corporações, ou seja, destes $10 \%$, no BP e nas NE, 50\% em cada. 
Tabela 2 - Tipos de demonstrações utilizadas pelas corporações para evidenciar as informações ambientais

\begin{tabular}{|c|c|c|c|c|c|c|c|c|c|c|c|c|c|}
\hline $\begin{array}{l}\text { Empresas/Informações } \\
\text { coletadas }\end{array}$ & 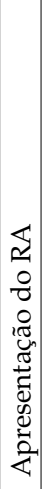 & 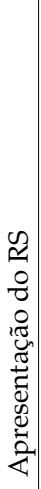 & 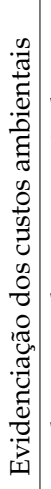 & 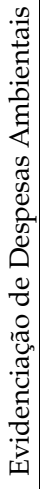 & 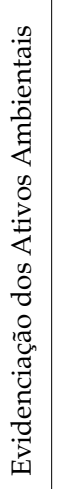 & 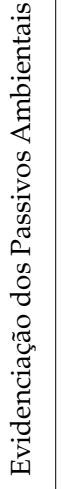 & 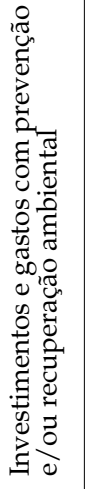 & 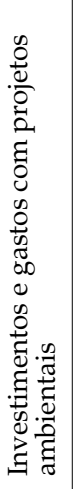 & 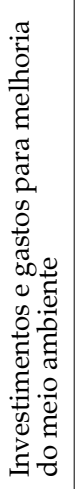 & 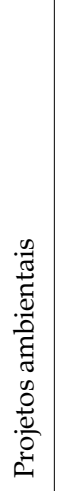 & 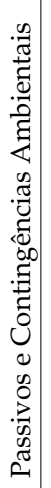 & 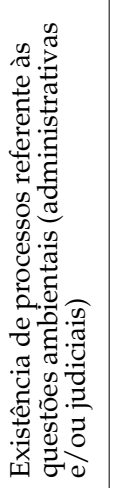 & 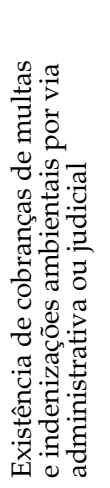 \\
\hline BANCO DO BRASIL S.A. & & 5 & & & & & 5 & 4,5 & 5 & 3,5 & & & \\
\hline VALE S.A. & & 5 & & & 3 & & $1,3,4,5$ & 4,5 & 4,5 & 5 & 1 & 3 & 3 \\
\hline $\begin{array}{l}\text { ITAU UNIBANCO HOLDING } \\
\text { S.A. }\end{array}$ & & 5 & & & & & & & & & & & \\
\hline BANCO BRADESCO S.A. & & 5 & & & & & & 5 & & 5 & & & \\
\hline $\begin{array}{l}\text { ULTRAPAR PARTICIPAÇÕES } \\
\text { S.A. }\end{array}$ & & 5 & & & & 1 & 4,5 & 4 & 4,5 & 4,5 & 3 & 3 & \\
\hline $\begin{array}{l}\text { BANCO SANTANDER BRASIL } \\
\text { S.A. }\end{array}$ & 6 & & & & & & 6 & 6 & & 6 & & & \\
\hline BRASKEM S.A. & 6 & & & & & & & & & 4,6 & & & \\
\hline GERDAU S.A. & 6 & 5 & & & & 1,3 & $4,5,6$ & $3,4,6$ & 4 & 6 & & & \\
\hline $\begin{array}{l}\text { METALÚRGICA GERDAU } \\
\text { S.A. }\end{array}$ & 6 & 5 & & & & 1,3 & $4,5,6$ & $3,4,6$ & 4 & 6 & & & \\
\hline TELEFONICA BRASIL S.A. & & 5 & & & & & & & & & & & \\
\hline BRF S.A. & & 5 & & & 1,3 & & 5 & & & & & 5 & \\
\hline $\begin{array}{l}\text { TELEMAR PARTICIPAÇÕES } \\
\text { S.A. }\end{array}$ & & 5 & & & & & & & & 5 & & & \\
\hline $\begin{array}{l}\text { CENTRAIS ELÉTRICAS } \\
\text { BRASILEIRAS S.A. - } \\
\text { ELETROBRAS }\end{array}$ & & 5 & 5 & & & & 5 & 4,5 & 5 & 4,5 & & & 5 \\
\hline TIM PARTICIPAÇÕES S.A. & 6 & 5 & & & & & & 5 & & 5 & & & \\
\hline CPFL ENERGIA S.A. & & 5 & & & & & 5 & 5 & 5 & 4,5 & & & \\
\hline $\begin{array}{l}\text { CIA ENERGÉTICA DE MINAS } \\
\text { GERAIS S.A. - CEMIG }\end{array}$ & & 5 & & & & & 5 & 4,5 & & & & 3 & \\
\hline \multicolumn{14}{|l|}{ SUL AMÉRICA S.A. } \\
\hline $\begin{array}{l}\text { CIA DE SANEAMENTO EST. } \\
\text { SÃO PAULO S.A.- SABESP }\end{array}$ & & 5 & & & & & 3,5 & 4,5 & & 3,4 & & 3,4 & \\
\hline $\begin{array}{l}\text { CIA PARANAENSE DE } \\
\text { ENERGIA - COPEL }\end{array}$ & & 5 & & 5 & & & & & & & & & 5 \\
\hline $\begin{array}{l}\text { ELETROPAULO METROP. } \\
\text { ELETRICIDADE DE SÃO } \\
\text { PAULO S.A. }\end{array}$ & & 5 & & & & & 5 & 0 & 3 & 5 & & & 3 \\
\hline
\end{tabular}

Fonte: Elaborado pelos autores. Legenda: Balanço Patrimonial [1]; DRE [2]; Notas Explicativas [3]; Relatório da Administração [4]; Relatório de Sustentabilidade [5]; Relatório Ambiental [6]. 
A existência de processos referente às questões ambientais (administrativos e/ou judiciais) foram evidenciados por $25 \%$ das corporações, principalmente nas NEs. A exposição de cobranças de multas e indenizações ambientais por vias administrativas e/ou judiciais foi apresentada por $20 \%$ das corporações tanto nas NE e no RS.

Estes resultados apontam que as corporações publicam as questões ambientais através do RS, em sua maioria, e também através de seus RL e NEs, corroborando com os resultados de Borba e Nazário (2003) e Souza, Rásia e Jaques (2010). O estudo de Ribeiro, Nascimento e Van Bellen (2009) também aponta que a demonstração contábil com maior environmental disclosure, no Brasil, são as NEs.

As questões ambientais (contingências, passivo ambiental e multas) são apresentadas de forma escassa por meio dos relatórios contábeis, tais como, o $\mathrm{BP}$, a DRE, ou seja, apenas em casos específicos e isolados. Esta situação reflete uma dificuldade na identificação das questões ambientais (contas genéricas), nos seus BP e na DRE, sendo necessário pesquisar em outros relatórios específicos para realizar esta distinção das questões ambientais, também apontados nos estudos de Nossa (2002), Ferreira e Silva (2006), Ribeiro e Van Bellen (2008), Rover, Borba e Murcia (2009) e Souza, Rásia e Jacques (2010). Esta dificuldade da identificação de contas ambientais no BP e DRE pode ser explicada em função da padronização sintética das normas estabelecidas pela Comissão de Valores Mobiliários (CVM) para a publicação dos relatórios contábeis. Portanto, são mínimas as contabilizações das questões ambientais, corroborando com os estudos de Carneiro e De Luca e Oliveira (2008).

Constata-se que as informações divulgadas retratam, principalmente, fatores de caráter positivo (investimentos e/ou projetos), ou seja, poucas corporações, e estas em poucos relatórios publicaram questões ambientais negativas (passivos, contingências e multas) que possuem o potencial de denegrir sua imagem institucional. Esta informação é confirmada no estudo de Imam (2000), Kuasirikun e Sherer (2004), Chatterjee e Mir (2008) e de Rover, Borba e Murcia (2009), afirmando que esta condição está voltada a Teoria da Divulgação Voluntária (TDV) (VERRECCHIA, 2001; DYE, 2001). Verrecchia (2001) e Dye (2001) apontam que a TDV enfatiza a publicação de questões positivas. Portanto, compreendendo corporações que possuem atividades com alta poluição, torna-se remoto imaginar que estas não agridem de forma significativa o meio ambiente, corroborado por Carneiro, De Luca e Oliveira (2008) e Rover, Borba e Murcia, (2009).

Nota-se que as evidenciações das informações ambientais divergem entre as corporações, assim como as informações apresentadas em cada uma dos relatórios, reforçado por Ferreira e Silva (2006). Esta diferença pode ser explicada em função da cultura dos gestores/empresa, pois a percepção da importância do tema pode variar. Outra questão é a falta de padronização na 
elaboração e divulgação ocorrendo de forma voluntária, crescente, mas não constante, corroborado por Calixto (2009).

\subsection{Resultados da correlação de Spearman e discussões}

Os resultados encontrados na aplicação da correlação de Spearman (TABELA 3) apontam que as corporações possuem uma correlação moderada ( $p$ $=0,575$ ) entre número de relatórios com a descrição de passivos ambientais e dos investimentos em prevenção e/ou recuperação ambiental. As corporações que utilizaram maior quantidade de relatórios para divulgarem seus investimentos em projetos ambientais, estes também apresentaram maior quantidade de relatórios com informações sobre os investimentos relacionados à prevenção e recuperação do meio ambiente (forte correlação, $p=0,729$ ).

Tabela 3 - Correlação de Spearman

\begin{tabular}{|c|c|c|c|c|c|c|c|c|c|c|c|c|c|c|c|c|c|}
\hline & 1 & 2 & 3 & 4 & 5 & 6 & 7 & 8 & 9 & 10 & 11 & 12 & 13 & 14 & 15 & 16 & 17 \\
\hline $\begin{array}{l}\text { Apresentação do Relatório } \\
\text { Ambiental [1] }\end{array}$ & 1,000 & & & & & & & & & & & & & & & & \\
\hline $\begin{array}{l}\text { Apresentação do Relatório de } \\
\text { Sustentabilidade [2] }\end{array}$ &,- 404 & 1,000 & & & & & & & & & & & & & & & \\
\hline $\begin{array}{l}\text { Evidenciação dos custos } \\
\text { ambientais [3] }\end{array}$ &,- 132 & , 096 & 1,000 & & & & & & & & & & & & & & \\
\hline $\begin{array}{l}\text { Evidenciação de Despesas } \\
\text { Ambientais [4] }\end{array}$ & $-1,132$ & $\mid$\begin{tabular}{|c|}
$\mid$ \\
\end{tabular} &,- 053 & 1,000 & & & & & & & & & & & & & \\
\hline $\begin{array}{l}\text { Evidenciação dos Ativos } \\
\text { Ambientais [5] }\end{array}$ & - -,192 & , 140 &,- 076 &,- 076 & 1,000 & & & & & & & & & & & & \\
\hline $\begin{array}{l}\text { Evidenciação dos Passivos } \\
\text { Ambientais [6] }\end{array}$ & 435 & |, 176 &,- 096 &,- 096 & $\mid-139$ & 1,000 & & & & & & & & & & & \\
\hline $\begin{array}{l}\text { Investimentos e gastos com } \\
\text { prevenção e/ou recuperação } \\
\text { ambiental [7] }\end{array}$ & 178 & | 191 & ,042 &,$- 250 \mid$ & ,305 &, $575^{*}$ & 1,000 & & & & & & & & & & \\
\hline $\begin{array}{l}\text { Investimentos e gastos com } \\
\text { projetos ambientais [8] }\end{array}$ &, 313 & | 241 & 228 &,- 249 &,- 032 & ,443 & , 729"* & 1,000 & & & & & & & & & \\
\hline $\begin{array}{l}\text { Investimentos e gastos para } \\
\text { melhoria do meio ambiente [9] }\end{array}$ &,- 091 & $\mid 330$ & 293 &,- 180 & 142 &, $452^{*}$ & ,667" & $493^{*}$ & 1,000 & & & & & & & & \\
\hline Projetos ambientais [10] & 288 &,- 087 &, 327 &,- 286 &,- 260 & 310 & 439 & ,442 &, $577^{\prime \prime}$ & 1,000 & & & & & & & \\
\hline $\begin{array}{l}\text { Passivos e Contingências } \\
\text { Ambientais [11] }\end{array}$ & -192 & , 140 &,- 076 &,-- 076 &, 389 &, 300 & $480^{*}$ &, 110 &, $588^{* *}$ & ,207 & 1,000 & & & & & & \\
\hline $\begin{array}{l}\text { Existência de processos } \\
\text { ambientais administrativos e } \\
\text { judiciais [12] }\end{array}$ &,- 330 & | $240 \mid$ &,- 131 & $\mid-, 131$ &, $574^{* *}$ & ,019 & ,478* & 177 & ,076 &,- 032 &, $494^{*}$ & 1,000 & & & & & \\
\hline $\begin{array}{l}\text { Existência de processos } \\
\text { referente às questões } \\
\text { ambientais (administrativas e/ } \\
\text { ou judiciais) [13] }\end{array}$ & $-2,287$ & , 209 &, 513 &, $513^{*}$ & 188 &,- 208 & ,089 &,- 022 &, 319 &,- 035 & , 188 &,- 054 & 1,000 & & & & \\
\hline Atividade [14] &,- 344 &,- 169 &,- 021 &,- 021 &,$- 465^{*}$ &,- 246 &,- 319 &,- 199 &,- 122 &,- 058 &, 007 &,- 207 &,- 192 & 1,000 & & & \\
\hline Anos de Atividade [15] &,- 030 &,- 012 & , 020 &,,- 020 & 206 &,$- 454^{*}$ & \begin{tabular}{|l|}
-414 \\
\end{tabular} &,$- 596^{*}$ &,$- 555^{*}$ & $-3,315$ &,- 219 & ,082 & ,049 & $-1,164$ & 1,000 & & \\
\hline Região/Sede [16] &,- 328 &,- 064 & ,231 &,- 316 &,- 049 &,$- 519^{*}$ &,- 201 &, 071 & ,053 &,- 028 & ,111 &, 067 & ,032 & ,347 &,- 115 & 1,000 & \\
\hline $\begin{array}{l}\text { Resultado (lucro ou prejuízo) } \\
\text { [17] }\end{array}$ & $-1,192$ & | $140 \mid$ & $688^{* *}$ &,- 076 & ,416 &,- 140 & ,318 & ,332 &, $507^{\star}$ & 193 & ,416 & 152 & ,663* & $\mid-248$ &,- 072 & , 336 & 1,000 \\
\hline
\end{tabular}

Fonte: Adaptada a partir do software IBM SSPS 21. Legenda: ** A correlação é significativa no nível 0,$01 ;{ }^{*}$ A correlação é significativa no nível 0,05 .

Os resultados também apontam que quanto maior é a quantidade de relatórios utilizados na evidenciação dos investimentos e gastos para melhoria do meio ambiente, maior é a quantidade de relatórios nos quais são 
evidenciados os passivos ambientais e os investimentos e gastos com prevenção e recuperação ambiental (forte correlação, $p=0,667$ ). Além disso, quanto maior a quantidade de relatórios que as corporações utilizam para evidenciar seus passivos e contingências ambientais, maior é a utilização dos mesmos para evidenciar seus investimentos e gastos em prevenção, recuperação e melhorias em relação ao meio ambiente (correlação moderada de $p=0,588$ ).

Com base nestes resultados percebe-se que as corporações evidenciam, principalmente, informações sobre os investimentos com projetos e/ou programas ambientais, relatando, também, maior preocupação em divulgar os investimentos relacionados à preservação, proteção e recuperação ambiental, bem como em melhorias com o meio ambiente, o que corrobora com Rover, Borba e Borgert (2008).

As evidenciações de ativos ambientais revelam uma correlação regular $(p=0,574)$ em relação à existência de processos ambientais administrativos e judiciais. O resultado (lucro ou prejuízo) das corporações demonstrou forte correlação $(p=0,688)$ em relação à evidenciação dos custos ambientais; e uma correlação forte $(p=0,663)$, em relação à existência de cobranças de multas e indenizações via cobrança administrativa ou judicial. Estas correlações revelam que quanto maior a quantidade de relatórios contábeis que evidenciam os custos ambientais, as cobranças de multas e indenizações via administrativa ou judicial, maior é a situação de prejuízo no mesmo exercício das corporações da ISE. Isto revela que a situação de prejuízo explica a divulgação das informações referente a custos, multas e indenizações ambientais, o que é aderente aos resultados de Braga et al. (2011). Porém, outros estudos (BRAGA; OLIVEIRA; SALOTTI, 2009; OLIVEIRA et al., 2009; ROVER et al., 2012) apontam que o resultado (lucro ou prejuízo) da corporação não é influenciado pela environmental disclosure.

A divulgação das corporações de informações ambientais, neste estudo, não apresenta um consenso e ou padronização. Uma explicação possível, desta constatação, pode ser em função das inúmeras variáveis que afetam a divulgação de informações ambientais e que não fizeram parte do escopo deste estudo, tais como: a) fatores culturais; b) contextos econômicos; c) o setor do estudo; entre outros, o que corrobora com Braga et al. (2011).

\section{Considerações finais}

O environmental disclosure nas corporações é crescente em termos de qualidade e quantidade, mas a passos lentos. Os principais resultados deste estudo revelam que as corporações da ISE analisadas evidenciam as informações ambientais, em especial, no RS. Neste sentido, a evidenciação ambiental (multas, contingencias, entre outros) é evidenciada, apenas pela minoria das corporações, através da escrituração convencional, ou seja, no BP e na DRE. 
As análises também revelam que o environmental disclosure abrange, na maioria, informações positivas, ou seja, poucas corporações evidenciaram informações negativas que poderiam denegrir sua imagem institucional. Já as corporações que evidenciaram informações negativas possuem uma correlação significativa com as informações positivas evidenciadas, ou seja, as informações positivas são evidenciadas em função da evidenciação de informações negativas.

A evidenciação das informações ambientais e a forma de apresentação das informações (descritiva, qualitativa, quantitativa) divergem entre as corporações, não apresentando um padrão. As análises também revelam que as corporações com resultados do período em situação de prejuízo, ou seja, que apresentaram prejuízo, possuem maior quantidade de disclosure ambiental e de relatórios que demonstram as informações de custos, multas e indenizações ambientais. Neste sentido, conclui-se que a environmental disclosure ocorre principalmente através do RS e do RL nas corporações com selo ISE, e as que mais evidenciam informações ambientais negativas compreendem as corporações com maior prejuízo contábil e, estas também são as que mais evidenciam informações positivas sobre as questões ambientais.

\section{REFERÊNCIAS}

BARBIERE, J. C. Gestão ambiental empresarial: conceitos, modelos e instrumentos. 2. ed. São Paulo: Saraiva, 2007.

BARDIN, L. Análise de conteúdo. 3a . Lisboa: Edições, v. 70, 2004.

BELKAOUI, A. The Impact of the disclosure of the environmental effects of organizational behavior on the market. Financial Management, v. 5, n. 4, p. 26, 1976.

BEN, F. Evidenciação de informações ambientais pelas empresas gaúchas. Revista Universo Contábil, v. 1, n. 3, p. 63-80, 2005.

BERGAMINI JUNIOR. S. Contabilidade e riscos ambientais. Revista do BNDES, n.11, 1999.

BERTHELOT, S; CORMIER, D; MAGNAN, M. Environmental disclosure research: review and synthesis. Journal of Accounting Literature, n. 22, p. 1-44, 2003.

BISQUERRA, R.; SARRIERA, J. C.; MARTINEZ, F. Introdução à Estatística: enfoque informático com o pacote estatístico SPSS. Porto Alegre: Artmed, 2004.

BM\&FBOVESPA. Índice de Sustentabilidade Empresarial - ISE. Disponível em: http:/ / www.bmfbovespa.com.br/indices/ResumoIndice. aspx?Indice=ISE\&Idioma=pt-br. Acesso em: 22 jun. 2014. 
BORBA, J. A., NAZÁRIO, L. Contabilidade ambiental: A preocupação empresarial com o meio ambiente através da evidenciação da terminologia comumente empregada nas demonstrações contábeis publicadas no Brasil. In: ENANPAD, XXVII, Anais... 2003. Atibaia: Anpad, 20 a 24 de set. 2003. p. 01-17.

BORGES, A. P.; ROSA, F. S.; ENSSLIN, S. R. Evidenciação voluntária das práticas ambientais: um estudo nas grandes empresas brasileiras de papel e celulose. Revista produção, v. 20, n. 3, p. 404-417, 2010.

BRAGA, C. Contabilidade Ambiental: Ferramenta para a gestão da sustentabilidade. São Paulo. Atlas, 2007.

BRAGA, J. P.; OLIVEIRA, J. R. S.; SALOTTI, B. M. Determinantes do nível de divulgação ambiental nas demonstrações contábeis de empresas brasileiras. Revista de Contabilidade da Universidade Federal da Bahia, v. 3, n. 3, p. 81-95, 2009.

BRAGA, C. et al. A influência da origem do controle acionário no nível de disclosure ambiental no setor de energia elétrica no Brasil. XXV ENCONTRO DA ANPAD. Rio de Janeiro, 2011. Anais... Rio de Janeiro, 2011.

BURGWAL, D. V.; VIEIRA, R. J. O. Environmental disclosure determinants in dutch listed companies. Rev. contab. finanç., v. 25, n. 64, p. 60-78, 2014.

CALIXTO, L. Contabilidade Ambiental: aplicação do modelo do ISAR no setor de mineração. 2004, 147f. Dissertação de Mestrado em Ciências Contábeis. Faculdade de Administração e Finanças, Universidade do Estado do Rio de Janeiro, Rio de Janeiro, 2004.

CALIXTO, L. Uma análise da evidenciação ambiental de companhias brasileiras-de 1997 a 2005. Contabilidade, Gestão e Governança, v. 10, n. 1, p. 1-32, 2009.

CAMPBELL, D. A longitudinal and cross-sectional analysis of environmental disclosure in UK companies - a research note. The British Accounting Review, n. 36, p. 107-117, 2004.

CARNEIRO, J. E.; DE LUCA, M. M. M.; OLIVEIRA, M. C. Análise das informações ambientais evidenciadas nas Demonstrações Financeiras das Empresas Petroquímicas Brasileiras listadas na Bovespa. Revista Contabilidade Vista e Revista, v. 19, n. 3, p. 39-67, 2008.

CARVALHO, G. M. B. Contabilidade Ambiental: teoria e prática. Curitiba. Juruá, 2007.

CHATTERJEE, B.; MIR, M. Z. The current status of environmental reporting by Indian companies. Managerial Auditing Journal, v. 23, n. 6, p. 609-629, 2008.

COSTA, C. A. G. Contabilidade Ambiental - mensuração, evidenciação e transparência. São Paulo. Atlas, 2012. 
COSTA, R. S.; MARION, J. C. A uniformidade na evidenciação das informações ambientais. Revista Contabilidade \& Finanças, v. 43, p. 20-33, 2007.

COWAN, S.; GADENNE, D. Australian corporate environmental reporting: a comparative analysis of disclosure practices across voluntary and mandatory disclosure systems. Journal of Accounting and Organizational Change, v. 1, n. 2, p. 165-179, 2005.

DYE, R. An evaluation of "essays on disclosure" and the disclosure literature in accounting. Journal of Accounting and Economics, v. 32, n. 1-3, p. 181-235, 2001.

DEEGAN, C.; RANKIN, M. Do Australian companies report environmental news objectively? An analysis of environmental disclosures by firms prosecuted successfully by the Environmental Protection Authority. Accounting, Auditing \& Accountability Journal, v. 9, n. 2, p. 50-67, 1996.

EPSTEIN, M. J. The identification, measurement, and reporting of corporate social impacts: past, present and future. Advances in Environmental Accounting and Management, v. 2, n. 1, p. 1-29, 2003.

FEIL, A. A.; NAIME, R. H. Mensuração da sustentabilidade das corporações com selo ISE da BMFBovespa via modelo GSE. Revista Ambiente Contábil, v. 7, n. 1, p. 254272, 2015.

FERREIRA, A. C. S. Contabilidade Ambiental: uma informação para o desenvolvimento sustentável. São Paulo. Atlas, 2003.

FERREIRA, A. C. S.; SIQUEIRA, J. R. M.; GOMES, M. Z. Contabilidade Ambiental e relatórios sociais. Atlas, 2009.

FERREIRA, L. F.; SILVA, M. W. Evidenciação da Contabilidade Ambiental: uma análise da transparência das demonstrações contábeis de empresas nacionais do setor siderúrgico. Revista Catarinense Da Ciência Contábil, v. 5, n. 15, p. 19-34, 2006.

FIELD, A. Descobrindo a estatística usando o SPSS. São Paulo: Artmed, 2009.

GALLON, A. V.; SOUZA, F. C.; ROVER, S.; VAN BELLEN, H. M. Um estudo longitudinal da produção científica em administração direcionada à temática ambiental. Revista Alcance, v. 15, n. 1, p. 81-101, 2008.

GRAY, R.; KOUHY, R.; LAVERS, S. Corporate social and environmental reporting: a review of the literature and a longitudinal study of UK disclosure. Accounting, Auditing and Accountability Journal, v. 8, n. 2, p. 47-77, 1995.

GRAY, R.; BEBBINGTON, J. Accounting for the environmental. 2nd ed. London: Sage, 2001. 
HUGHES, S. B.; ANDERSON, A.; GOLDEN, S. Corporate Environmental Disclosures: Are They Useful in Determining Environmental Performance? Journal of Accounting and Public Policy, n. 20, p. 217-240, 2001.

IMAM, S. Corporate social performance reporting in Bangladesh. Managerial Auditing Journal, v. 15, n. 3, p. 133-141, 2000.

ISE - Índice de Sustentabilidade Empresarial. 2014. Disponível em: <https:/ / www. isebvmf.com.br/index.php? $r=$ publicacoes/view\&id=377>. Acesso em: 23 de Jan. de 2015.

KUASIRIKUN, N.; SHERER, M. Corporate social accounting disclosure in Thailand. Accounting, Auditing and Accountability Journal, v. 17, n. 4, p. 629-660, 2004.

LEONARDO, V. S. A contabilidade e o meio ambiente: uma visão das indústrias químicas certificadas pela ISO 14000. 2001. 151f. Dissertação de Mestrado em Engenharia de Produção, Universidade Federal de Santa Catarina, Florianópolis, SC, 2001.

LIMA, K. P. S.; CUNHA, D. R.; MOREIRA, F. G. L.; PORTE, M. S. Contabilidade Ambiental: um estudo sobre a evidenciação das informações ambientais nas demonstrações contábeis das grandes empresas brasileiras. Revista Eletrônica de Administração, v. 11, n. 1, p. 1-14, 2012.

MIRANDA, W. B.; MALAQUIAS, R. F. Análise do nível de evidenciação ambiental de empresas brasileiras que negociam ADRS na Bolsa de Valores de Nova Iorque. Revista Ambiente Contábil, v. 5, n. 1, p. 93 - 111, 2013.

MITRA A.; LANFORKD, S. Research methods in park, recreation and leisure services. Champaign: Sagamore Publishing, 1999.

MURRAY, A.; SINCLAIR, D.; POWER, D.; GRAY, R. Do Financial Markets care about social and environmental disclosure? Further evidence and exploration from the UK. Accounting, Auditing \& Accountability Journal, v. 19, n. 2, p. 228-255, 2006.

MURCIA, F. D. R.; ROVER, S.; LIMA, I.; FÁVERO, L. P. L.; LIMA, G. A. S. F. 'Disclosure verde' nas demonstrações contábeis: características da informação ambiental e possíveis explicações para a divulgação voluntária. Revista UnB Contábil, n. 1-2, p. 260-278, 2008.

NISKALA, M.; PRETES, M. Environmental reporting in Finland: a note on the use of annual reports. Accounting, Organization and Society, v. 20, n. 6, p. 457-466, 1995.

NOSSA, V. Disclosure ambiental: uma análise do conteúdo dos relatórios ambientais de empresas do setor de papel e celulose em nível internacional. 2002. $246 \mathrm{f}$. Tese (Doutorado em Controladoria e Contabilidade) - FEA/USP, São Paulo. 2002. 
O'DONOVAN, G.; GIBSON, K. Environmental disclosures in the corporate annual report: A longitudinal Australian study. In: 6th Interdisciplinary Environmental Association Conference. 2000. p. 21-25.

OLIVEIRA, M. C.; DE LUCA, M. M. M.; PONTE, V. M. R.; PONTES JUNIOR, J. E. Divulgação de informações sociais por empresas brasileiras segundo os indicadores de responsabilidade social corporativa da ONU. Revista contabilidade financeira, v. 20, n. 51, p. 116-132, 2009.

PAIVA, P. R. Contabilidade Ambiental. São Paulo: Atlas S.A., 2009.

PATTEN, D. M. The relation between environmental performance and environmental disclosure: a research note. Accounting, Organization and Society, n. 27, p. 763-773, 2002.

RIBEIRO, A. M.; VAN BELLEN, H. M. Evidenciação ambiental: uma comparação do nível de evidenciação entre os relatórios de empresas brasileiras. In: CONGRESSO USP DE CONTABILIDADE E CONTROLADORIA, 8., 2008, São Paulo. Anais... São Paulo: FEA-USP, 2008.

RIBEIRO, A. M.; NASCIMENTO, L. F.; VAN BELLEN, H. M. Evidenciação ambiental: análise comparativa multissetorial entre Brasil, Estados Unidos e Inglaterra.

Contextus - Revista Contemporânea de Economia e Gestão, v. 7, n. 1, p. 7-22, 2009.

RIBEIRO, M. S. Contabilidade Ambiental. São Paulo. Saraiva, 2006.

ROSA, F. S.; ENSSLIN, S. R.; ENSSLIN, L.; LUNKES, R. J. Gestão da evidenciação ambiental: um estudo sobre as potencialidades e oportunidades do tema. Eng. Sanit. Ambient., v. 16, n. 2, p. 157-166, 2011.

ROVER, S.; TOMAZZIA, E. C.; MURCIA, F. D.; BORBA, J. A. Explicações para a divulgação voluntária ambiental no Brasil utilizando a análise de regressão em painel. Rev. Adm., v. 47, n. 2, 217-230, 2012.

ROVER, S.; BORBA, J. A. A Evidenciação das Informações Ambientais nas Demonstrações Contábeis das Empresas que Atuam no Brasil e Negociam ADRs na Bolsa de Valores dos Estados Unidos: Uma Análise das DFP'S (CVM) e do Relatório 20-F (SEC). In: Congresso USP de Controladoria e Contabilidade. 2006.

ROVER, S.; ALVES, J. L.; BORBA, J. A. A evidenciação do passivo ambiental: quantificando o desconhecido. Revista contemporânea em contabilidade, v. 5, n. 1, p. 41-58, 2006.

ROVER, S.; BORBA, J. A.; BORGERT, A. Como as empresas classificadas no Índice de Sustentabilidade Empresarial (ISE) evidenciam os custos e investimentos ambientais. Custos e @gronegócio on line, v. 4, n. 1, p. 1-25, 2008.

ROVER, S.; BORBA, J. A.; MURCIA, F. D. Características do disclosure ambiental de empresas brasileiras potencialmente poluidoras: análise das demonstrações 
financeiras e dos relatórios de sustentabilidade do período de 2005 a 2007. Contextus Revista Contemporânea de Economia e Gestão, v. 7, n. 1, p. 23-36, 2009.

SANTOS, A. O.; SILVA, F. B.; SOUZA, S.; SOUSA, M. F. R. Contabilidade ambiental: um estudo sobre sua aplicabilidade em empresas brasileiras. Contabilidade \& Finanças, v. 16, n. 27, p. 89-99, 2001.

SOUZA, M. A.; RÁSIA, K. A.; JACQUES, F. V. S. Evidenciação de informações ambientais pelas empresas integrantes do índice de sustentabilidade empresarial ISE. Rev. Cont. e Controladoria, v. 2, n. 1, p. 51-139, 2010.

SOUZA, V. R.; RIBEIRO, M. S. Aplicação da contabilidade ambiental na indústria madeireira. Revista Contabilidade \& Finanças, v. 35, n. p. 54-67, 2004.

TINOCO, J. E. P.; KRAEMER, M. E. P. Contabilidade e Gestão Ambiental. 3. ed. Atlas, 2011.

VERRECCHIA, R. Essays on disclosure. Journal of Accounting and Economics, v. 32, n. 1-3, p. 97-180, 2001.

WISEMAN, J. An evaluation of environmental disclosures made in corporate annual reports. Accounting, Organization and Society, v. 7, n. 1, p. 553-563, 1982. 